\title{
Regulation of osteopontin and related proteins in rat CC531 colorectal cancer cells
}

\author{
RANIA GEORGES ${ }^{1 *}$, HASSAN ADWAN $^{1 *}$, MARIA ZHIVKOVA $^{1}$, ERGÜL EYOL $^{1}$, \\ FRANK BERGMANN $^{2}$ and MARTIN R. BERGER ${ }^{1}$ \\ ${ }^{1}$ Toxicology and Chemotherapy Unit, German Cancer Research Center (DKFZ), INF 581; \\ ${ }^{2}$ Department of Surgery, University of Heidelberg, INF 110, 69120 Heidelberg, Germany
}

Received January 19, 2010; Accepted March 15, 2010

DOI: 10.3892/ijo_00000672

\begin{abstract}
Colorectal cancer accounts for $11 \%$ of all cancers and is the second most frequent cause of cancer-related death, with the majority of deaths attributable to hepatic metastasis. The main aim of the study was to investigate changes which occur in CC531 rat colon adenocarcinoma cells and are instrumental to the metastatic phenotype after homing to the liver. RT-PCR and Western blotting were used to detect the expression of certain proteins, transcription factors and enzymes, which are intimately linked to colorectal metastasis. These included osteopontin (OPN), bone sialoprotein 11 (BSP 11), Runx2, Hoxc8, matrix metalloprotease-7 (MMP-7) and matrix-metalloprotease-9 (MMP-9). Subsequently, in order to detect the role of the hepatocytes in these changes seen in tumor cells, two models of co-culturing hepatocytes with CC531 cells were established. OPN, Runx2 and MMP-7 were found to be highly expressed in CC531 metastases explanted from the liver, but showed subsequent down-regulation and/or disappearance in cell culture. The inverse regulation of Hoxc8, OPN and Runx2 suggests that these genes may be regulated in a feed-back loop manner. MMP-9 mRNA and active MMP-7 protein were expressed in tumor cells themselves. The presence of hepatocytes was insufficient to induce induction of OPN and Runx2 in tumor cells in vitro, so was the addition of OPN or TGF- $\beta 1$. Whereas TGF- $\beta 1$ induced over-expression of OPN and Runx2 in hepatocytes, it did not exert the same effect on hepatocytes co-cultured with CC531 cells, indicating that this response was abrogated by CC531 cells.
\end{abstract}

Correspondence to: Dr Martin R. Berger, Toxicology and Chemotherapy Unit, German Cancer Research Center (DKFZ), Im Neuenheimer Feld 581, D-69120 Heidelberg, Germany

E-mail: m.berger@dkfz-heidelberg.de

*Contributed equally

Key words: hepatocytes, co-culture, SIBLINGs, Hoxc8, CC531 cells

\section{Introduction}

Colorectal cancer is one of the most common malignant tumors and a major cause of cancer death in developed countries. Over 700,000 men and women are found to have colorectal cancer globally each year (1). Liver metastases are detected in $20 \%$ of all patients undergoing resection of their primary colorectal tumor (2). In these patients, resection is the only curative treatment but this treatment is possible in only $10 \%$ of the patients and results in a 5-year survival rate of $22-44 \%$ (3-6).

There is a continuous shedding of tumor cells from a primary colorectal cancer and these cells are transported by the blood stream to the liver, the first capillary filter (7). Clearly, not all disseminated colorectal cancer cells develop into macrometastases (8). Therefore, it was hypothesized that sub-populations of malignant cells evolve certain genetic advantages to form distant metastasis. These include the capability to adhere, evade the immune system, to invade and survive in their new hepatic environment. Some of these properties have been linked to proteins of the extracellular matrix such as OPN. In this study, the expression and regulation of this matricellular protein as well as of BSP 11 and their transcription factors (Runx2, Hoxc8) were analyzed.

OPN and BSP 11 belong to the SIBLING (small integrinbinding ligand, N-linked glycoprotein) family of secreted non-collagenous glycoproteins, which are involved in different cancers and their metastases. Runx2, a member of the RUNX (Runt-related) gene family, is known to be a transcription factor of OPN and BSP 11, and consequently, associated with tumor metastasis. Hoxc8 is a member of the evolutionaryconserved homeobox genes, which comprise a large and essential family of developmental regulators. Therefore, deregulation of these genes is supposed to be tightly implicated in oncogenesis and carcinogenesis. In addition, MMP-7 and MMP-9 were analyzed, which are known as metalloproteases that are intimately linked to colorectal cancer metastasis. They belong to the MMP family of zinc atomdependent endopeptidases with specific and selective activities against many components of the extracellular matrix. Furthermore, they are known to interact with OPN and BSP 11.

The main aim of the study was to investigate changes which occur in rat CC531 colon adenocarcinoma cells and 
are instrumental to the metastatic phenotype after homing to the liver. The 'seed and soil' hypothesis, which was first proposed by Paget, provoked the second main question in this study: Do the hepatocytes, as one of the main compartments in this 'soil', play a key role in the changes seen in tumor cells? In order to answer these questions, hepatocytes were isolated and used in two co-culture models aiming to mimic the microenvironment found in the metastatic liver as closely as possible.

\section{Materials and methods}

Cell culture. The CC531 colon adenocarcinoma cell line was established from a 1,2-dimethylhydrazine-induced rat colon adenocarcinoma. CC531 cells were maintained in RPMI1640 medium (Invitrogen, Karlsruhe), supplemented with $10 \%$ fetal calf serum (FCS), L-glutamine $(2 \mathrm{mM})$, penicillin (100 IU/ml), and streptomycin (100 $\mu \mathrm{g} / \mathrm{ml})$ (Invitrogen). The cells were kept at $37^{\circ} \mathrm{C}$ in a humidified incubator with an atmosphere of $5 \% \mathrm{CO}_{2}$. For isolation and propagation, cells were washed with phosphate-buffered saline (PBS), trypsinised ( $0.25 \%$ trypsin/EDTA), pelleted at $1500 \mathrm{rpm}$ for $5 \mathrm{~min}$, and counted in a Neubauer chamber and suspended at a concentration of $5 \times 10^{5}$ cells $/ \mathrm{ml}$ in William's medium-E (Invitrogen).

Rat hepatocyte isolation. Hepatocyte suspensions were prepared from livers of 6-8 weeks old male WAG/Rij rats (Charles River, Germany) fed a standard diet ad libitum. After an adaptation period of 1 week the rats were used for hepatocyte isolation, which was performed by perfusion with collagenase as described by others (9). For this purpose, collagenase Type IV (Serva, Heidelberg, Germany) was used. The animal experiments were approved by the responsible governmental Animal Ethics Committee (Regierungspräsidium Karlsruhe, Germany).

After complete disaggregation of liver cells, the resulting suspension was filtered through a sterile filter (Cell strainer, $70 \mu \mathrm{m}$ Nylon) into $50 \mathrm{ml}$ tubes and the cells were centrifuged three times $\left(400 \mathrm{U} / \mathrm{min}, 10^{\circ} \mathrm{C}, 10 \mathrm{~min}\right.$, respectively). After the first centrifugation the supernatant was discarded and the cells were resuspended in fresh medium and centrifuged two times more. The final cell pellet was taken up in maintenancemedium without FCS.

Trypan blue exclusion ( 1 part trypan blue: 2 parts cell suspension) was used for cell counting and assessing their viability by using a hemocytometer. Cells $\left(4 \times 10^{7}\right)$ with $98 \%$ viability were usually obtained from one rat liver.

Co-culture/two compartment model. The liver cell suspension was diluted with maintenance-medium E (without FCS) to yield the required final cell density $\left(1 \times 10^{6}\right.$ cells $\left./ 2 \mathrm{ml} / \mathrm{well}\right)$ and plated into 6-well-dishes coated with collagen. After $2 \mathrm{~h}$ the medium was removed and new medium (with 5\% FCS) was added.

After changing the medium the next day, a polycarbonate filter $(0.4 \mu \mathrm{m}$ pore size $)$ was placed into each well. CC531 cells $\left(4 \times 10^{5}\right)$ per $\mathrm{ml}$ maintenance medium were transferred onto this filter. After 24 h, CC531 cells were harvested from the upside of the filter using cell scrapers. Then the cell suspension was centrifuged at $3000 \mathrm{rpm}$ for $5 \mathrm{~min}$ and the resulting pellet was immediately frozen at $-80^{\circ} \mathrm{C}$.
The hepatocytes were also taken up with PBS after removing the filters and their medium, and were then centrifuged and frozen as detailed for the CC531 cells. Both cell types were harvested after 48 and $72 \mathrm{~h}$. The medium was changed every day during the experiment, by removing half of the volume and adding the same amount fresh medium.

Co-culturelone compartment model. The hepatocytes and CC531 cells were seeded subsequently into a common well. First, the isolated hepatocytes were plated into 6-well-plates (for concentrations see below) and the medium was changed after $2 \mathrm{~h}$. At this point, the CC531 suspension was added to the wells containing the hepatocytes and plated at a density of $2.5 \times 10^{5}$ CC531/1 ml maintenance E medium. Half of these wells were additionally treated with recombinant human TGF- $\beta 1$ (end concentration of $10 \mathrm{ng} / \mathrm{ml}$; Chemicon, Hofheim, Germany) as shown: a) $10^{6}$ hepatocytes $/ 2 \mathrm{ml}$ medium as control; b) as for (a) followed by adding of TGF-ß1 (10 ng/ml; end concentration); c) $5 \times 10^{5} \mathrm{CC} 531 / 2 \mathrm{ml}$ medium as control; d) as for (c) followed by adding of TGF- $31(10 \mathrm{ng} / \mathrm{ml}$; end concentration $)$; e) $\left(5 \times 10^{5}\right.$ hepatocytes $+25 \times 10^{4}$ CC531) $/ 2 \mathrm{ml}$ medium as control; f) as for (e) followed by adding of TGF- 31 (10 ng/ml; end concentration).

After $24 \mathrm{~h}$ from adding TGF- $\$ 1$, the cells were harvested, as mentioned above, by removing the medium and washing the cells several times with PBS. The cells were then centrifuged at $3000 \mathrm{rpm}$ for $5 \mathrm{~min}$ and the pellets were frozen at $-80^{\circ} \mathrm{C}$. Plates treated in parallel were harvested after 72 and $96 \mathrm{~h}$. During this time, the medium was changed once, by removing $1 \mathrm{ml}$ and adding the same volume fresh medium, taking into account the appropriate addition of TGF- $B 1$ when necessary. The whole experiment was repeated as described, but by using recombinant human OPN (final concentration $10 \mu \mathrm{g} / \mathrm{ml}$ ) (EMP Genetech) instead of TGF-ß1.

RNA-isolation and RT-PCR. The RNeasy mini-kit (Qiagen, Hilden, Germany) was used for RNA-isolation from CC531 cells and hepatocytes. The amount and purity of isolated RNA was measured in a spectrophotometer using the 260/ 280 ratio.

To produce cDNA from the isolated RNA, a reaction mixture of 100 ng RNA, buffer (1X), dNTP's (5 $\mu \mathrm{M})$, oligodT-primers $(1 \mu \mathrm{M})$, RNAse inhibitor (10 units) and reverse transcriptase (4 units) was incubated in a total volume of $20 \mu \mathrm{l}$ at $37^{\circ} \mathrm{C}$ for $1 \mathrm{~h}$. cDNA $(2 \mu \mathrm{l})$ was mixed with $\mathrm{MgCl}_{2}$ (1.75 mM), dNTPs $(200 \mu \mathrm{M})$, buffer $(1 \mathrm{X})$, red taq DNA polymerase (2.5 units) and the selected primer pair (each $0.5 \mu \mathrm{M})$.

The respective primer sequences were as follows: OPN (cggtgaaagtggctgagttt, cagcatctgagtgtttgctgt), BSP 11 (tgccact cactcacttgctc, gcagtcttcattttgcaatttct), Runx2 (gaagaacgcatcat cacagg, tctgcagggtctcttctgttt), Hoxc8 (gacaaggccacttaaatca aaac, tgtaagtttgccgtccactg), MMP-9 (cctctgcatgaagacgacataa, ggtcaggtttagagccacga) and $\gamma$ tubulin (gatggcagtgacagcctagag, gccgttccaagaggtagga).

The reaction mixture was incubated in a thermal cycler (DNA engine, PTC200 Peltier, USA). The resulting amplicons were separated on a polyacrylamide gel in TBE buffer (10.8 g Tris-base, $5.5 \mathrm{~g}$ boric acid, $0.74 \mathrm{~g}$ EDTA and $\mathrm{H}_{2} \mathrm{O}$ to $200 \mathrm{ml}$ ) at $180 \mathrm{~V}$ for $2 \mathrm{~h}$. After electrophoresis the gel was 


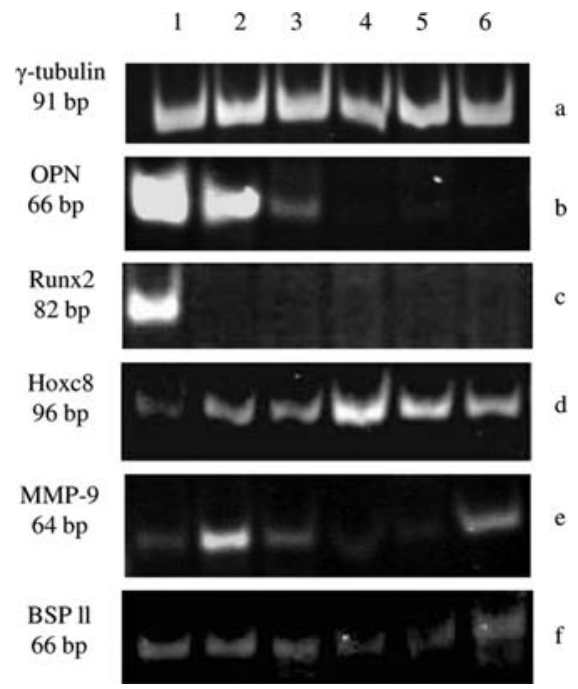

Figure 1. OPN, Runx2, Hoxc8, MMP-9 and BSP 11 mRNA as detected by RT-PCR. Lane 1, CC531 cells explanted from the tumor; lanes (2-6), CC531 cells after $11,13,15,18$ and 21 days, respectively.

incubated in ethidium bromide for 10 min followed by visualization under UV-light (Gel Doc XR, BIO-RAD, Munich).

Western blotting. Cell pellets were thoroughly suspended, lysed, heated at $99^{\circ} \mathrm{C}$ for $5 \mathrm{~min}$, and then centrifuged at $10,000 \mathrm{rpm}$ for $10 \mathrm{~min}$, at $4^{\circ} \mathrm{C}$. In order to load the same amount of protein from each sample, protein concentration of lysates was determined by using the BCA protein assay kit (Pierce, USA). A volume containing 30-40 $\mu \mathrm{g}$ protein was separated (X-cell Sure Lock system, Invitrogen) on 4-12\% Bis-Tris gels (NuPAGE, Invitrogen) in SDS running buffer at $200 \mathrm{~V}$ for $1 \mathrm{~h}$.

As reference, $15 \mu 1$ of full range rainbow marker (Fermentase, Germany) was run with the lysates. The separated proteins were transferred onto PVDF membranes (Roche, Mannheim, Germany) at room temperature using a semi-dry system based on Whatman papers wetted with transfer buffer $(3 \mathrm{~g}$ Tris-Base $+14.4 \mathrm{~g}$ glycin $+200 \mathrm{ml}$ methanol) for $90 \mathrm{~min}$ at a current of $0.8 \mathrm{~mA} / \mathrm{cm}^{2}$ and a voltage of $\sim 15 \mathrm{~V}$. The membranes were blocked for $1 \mathrm{~h}$ in blocking solution (PBS $+5 \%$ dry milk), and then incubated with the first antibody (diluted 1:500 in PBS pH $7.5+0.1 \%$ dry milk $+0.1 \%$ Triton $\mathrm{X}-100$ ) on a shaker at $4^{\circ} \mathrm{C}$ overnight. The following primary antibodies [Mouse monoclonal OPN (AKm2A1), goat polyclonal PEBP2 $\alpha \mathrm{A} / \mathrm{Runx} 2$ (S-19), goat polyclonal MMP-7 (D-15), mouse monoclonal ERK 2 (D-2) and goat polyclonal GAPDH (V-18)] and their corresponding secondary antibodies were obtained from Santa-Cruz, Heidelberg. The blots were washed three times followed by an incubation step with the appropriate secondary antibody (1:4000 dilution) for 45 min on a shaker at room temperature. A second washing step was repeated four times before developing the membranes with ECL (Amersham Biosciences). For re-probing, the PVDF membranes were stripped in stripping solution (6.25 $\mathrm{ml} 1 \mathrm{M}$ Tris- $\mathrm{HCl} \mathrm{pH} 6.8,20 \mathrm{ml}$ 10\% SDS, millipore- $\mathrm{H}_{2} \mathrm{O}$ ad $100 \mathrm{ml}$ ) by incubating at $56^{\circ} \mathrm{C}$ for $30-40 \mathrm{~min}$. Then the membranes were washed for $5 \mathrm{~min}$ followed by the same procedure as mentioned above.

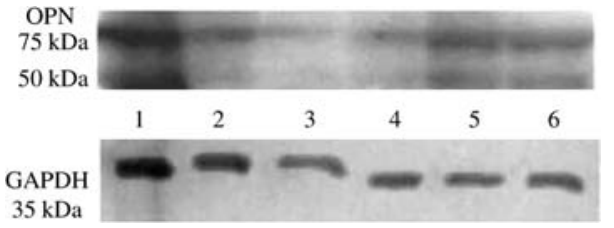

Figure 2. OPN protein expression as detected by Western blot. Lane 1, CC531 cells explanted from the tumor; lanes (2-6), CC531 cells after 11, 13, 15,18 and 21 days, respectively.

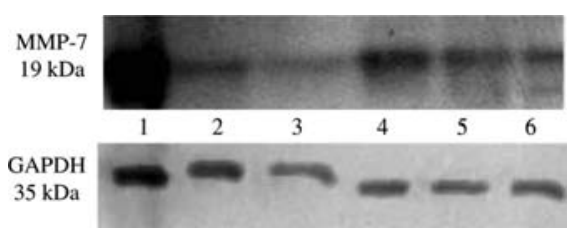

Figure 3. MMP-7 protein expression as detected by Western blot. Lane 1, CC531 cells explanted from the tumor; lanes (2-6), CC531 cells after 11, 13, 15,18 and 21 days, respectively.

\section{Results}

Use of CC531 cells ex vivo. After explanting the liver, a piece of liver containing tumor cells was resected and used for re-culturing CC531 cells. These cells were cultured for three weeks and within this period passaged five times corresponding to $11,13,15,18$ and 21 days, respectively (passages 1-5). At these intervals the cells were investigated for their mRNA and/or protein expression levels of OPN, BSP 11, Runx2, Hoxc8 and MMPs.

OPN expression profile. At the mRNA level, OPN was up-regulated in CC531 cells explanted from the tumor. Over time, OPN mRNA level gradually decreased until it disappeared after the third passage; i.e. after two weeks (corresponding to a reduction by $88 \%$; Fig. 1b).

The OPN protein level, as shown by Western blot (Fig. 2), was first highly expressed but then down-regulated to minimally $5 \%$ within the next 15 days. A slight increase to $20 \%$ of the initial level was seen at the final passages 4 and 5 .

Runx 2 expression profile. At the mRNA level, Runx 2 was highly transcribed in tumor cells growing in the liver and then it totally disappeared under culture conditions without subsequent up-regulation (Fig. 1c). In accord with the RNA, the expression of the Runx 2 protein was relatively high at the beginning but then was completely down-regulated (data not shown).

MMPs expression profile. RT-PCR revealed that MMP-9 mRNA showed a behavior different from that of the other genes investigated. In tumor cells growing in the liver, MMP-9 mRNA was transcribed at a relatively low level, but in culture the metalloprotease was up-regulated $\sim 3$-fold after ten days (the first passage) compared to the initial level. Afterwards the expression of MMP-9 was reduced in the next three passages (down to $50 \%$ of the initial level), and then returned to the high level (3-fold increase over the initial level) after three weeks (Fig. 1e).

MMP-7 was investigated only at the protein level (Fig. 3). A $19 \mathrm{kDa}$ band was observed. After culturing the cells in vitro 


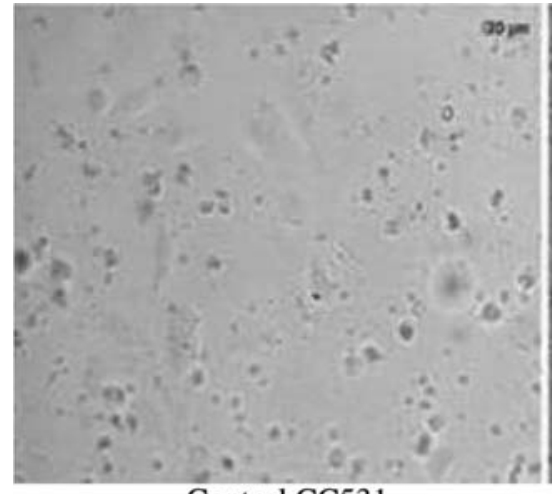

Control CC531

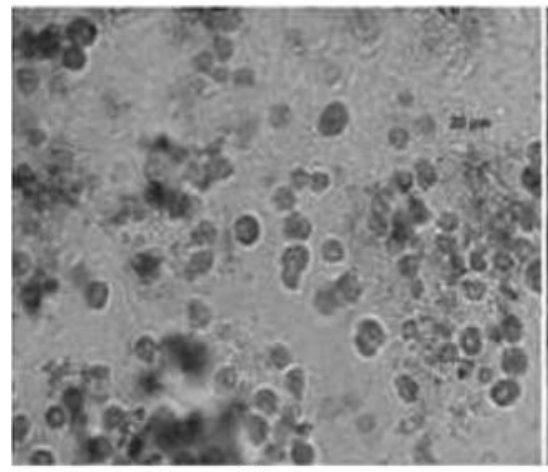

Control hepatocytes

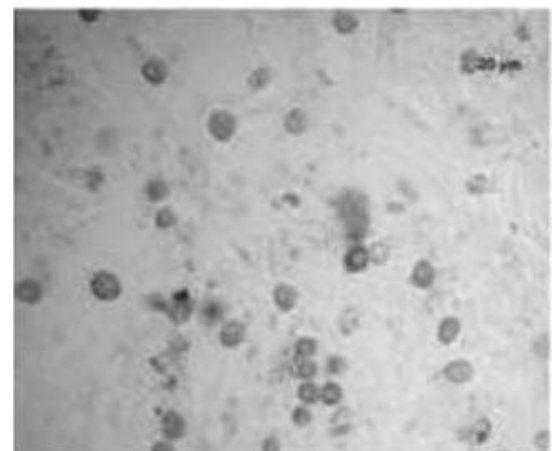

Control CC531+hepatocytes

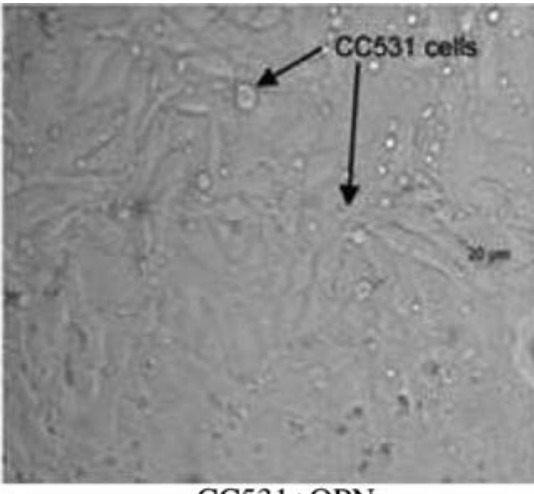

CC531+OPN

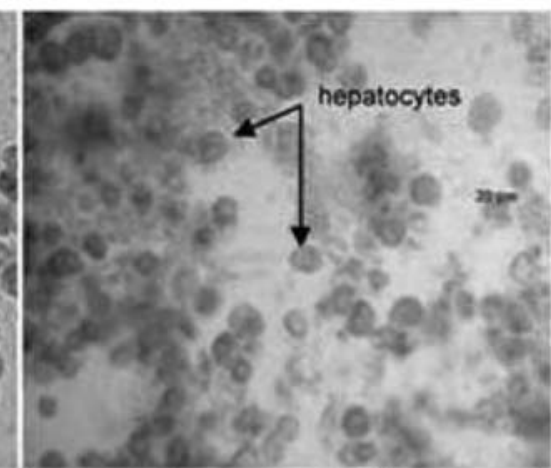

Hepatocytes+OPN

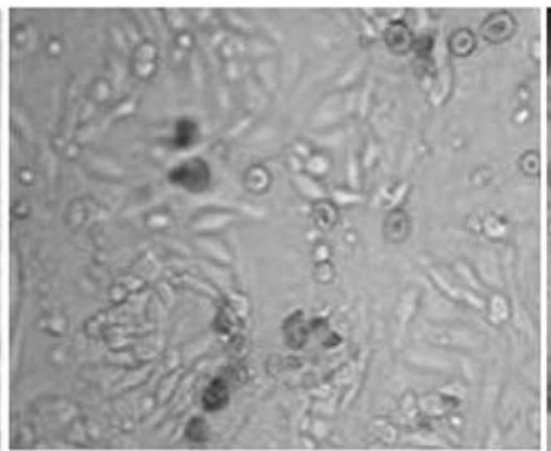

CC531+hepatocytes+OPN
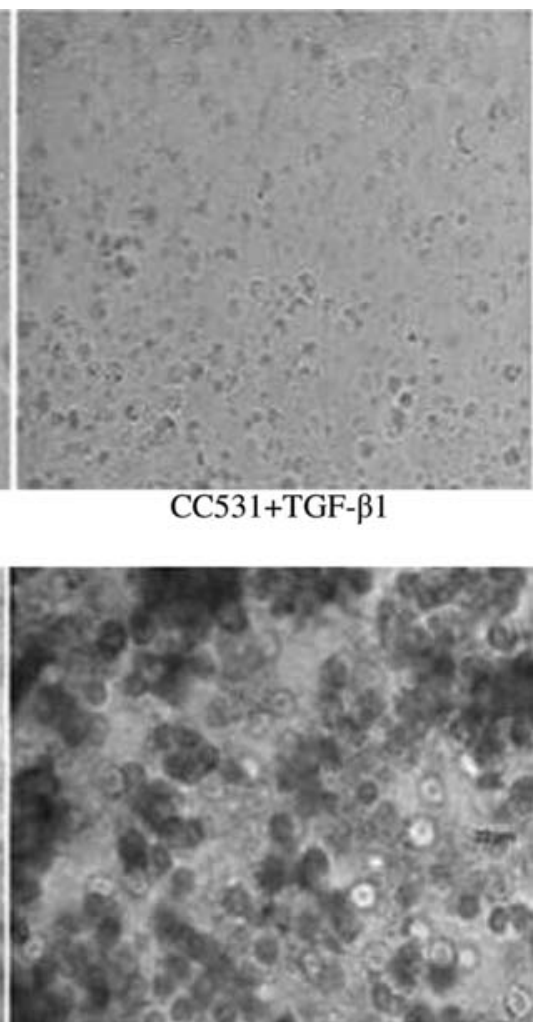

Hepatocytes+TGF- $\beta 1$

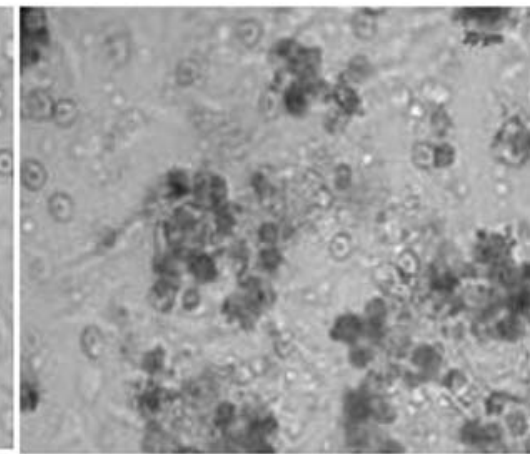

CC531+hepatocytes+TGF- $\beta 1$

Figure 4. Microscopic aspect of CC531 rat colorectal carcinoma cells and hepatocytes. The figure shows the positive influence of $10 \mu \mathrm{g} / \mathrm{ml}$ rhOPN on the growth of CC531 cells and hepatocytes compared to controls (larger and in better condition). In contrast to OPN, addition of 10 ng/ml rhTGF- 31 caused cell death to the majority of cells and the surviving cells were smaller and seemed to be less differentiated than untreated control cells. Magnification x200, the bars indicate a distance of $20 \mu \mathrm{m}$.

MMP-7 was down-regulated within two weeks, followed by an increased expression for the next three passages.

Hoxc8 expression profile. In order to investigate the possible relationship between the expression profile of Hoxc8 and OPN, Hoxc8 mRNA levels were determined by RT-PCR. Interestingly, an inverse correlation was observed between Hoxc8 and OPN mRNA levels in CC531 cells. A faintly expressed 96-bp band was detected in the explanted CC531 cells, but in cell culture Hoxc8 mRNA levels increased gradually to $>10$-fold above the initial level after two weeks. Then the expression decreased by $\sim 50 \%$ of the peak level and remained at this level for the subsequent passages (Fig. 1d).

BSP ll expression profile. As shown by the 66-bp band, a detectable BSP 11 mRNA level was found in freshly explanted tumor cells. This level was only slightly reduced within passages $1-4$, but then increased considerably ( $>2$-fold above the initial level) at passage 5 (Fig. 1f).

Co-culture/two compartment model. The expression of OPN and Runx 2 was investigated on mRNA and protein levels. There were no detectable levels in co-cultured CC531 cells (data not shown).

\section{Co-culturelone compartment model.}

Microscopic aspect. Hepatocytes and CC531 cells were photographed under the microscope after $96 \mathrm{~h}$ of adding OPN or TGF- $ß 1$. Initially, both OPN and TGF- $ß 1$ stimulated the growth of treated cells. Interestingly, after four days significant differences became apparent. 


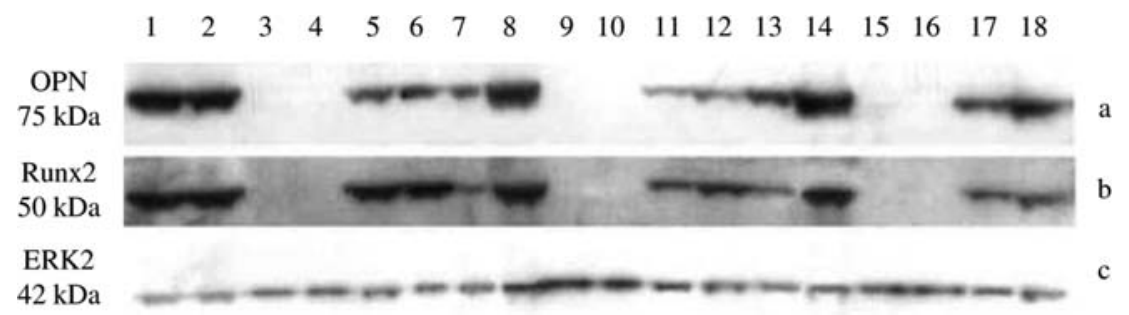

Figure 5. OPN (a), Runx2 (b) and ERK2 (c) protein expression in response to rhTGF- 31 in CC531 cells and hepatocytes as detected by Western blot. Lanes 1 , 7 and 13, control hepatocytes after 24, 72 and $96 \mathrm{~h}$, respectively. Lanes 2,8 and 14, hepatocytes $+10 \mathrm{ng} / \mathrm{ml}$ rhTGF- $\beta 1$ after 24,72 and $96 \mathrm{~h}$, respectively. Lanes 3, 9 and 15, control CC531 cells after 24, 72 and $96 \mathrm{~h}$, respectively. Lanes 4, 10 and 16, CC531 cells $+10 \mathrm{ng} / \mathrm{ml}$ rhTGF- $\beta 1$ after 24, 72 and 96 h, respectively. Lanes 5, 11 and 17, control co-cultured CC531 cells and hepatocytes after 24, 72 and 96 h, respectively. Lanes 6, 12 and 18, co-cultured CC531 cells and hepatocytes $+10 \mathrm{ng} / \mathrm{ml}$ rhTGF- $\beta 1$ after 24,72 and $96 \mathrm{~h}$, respectively

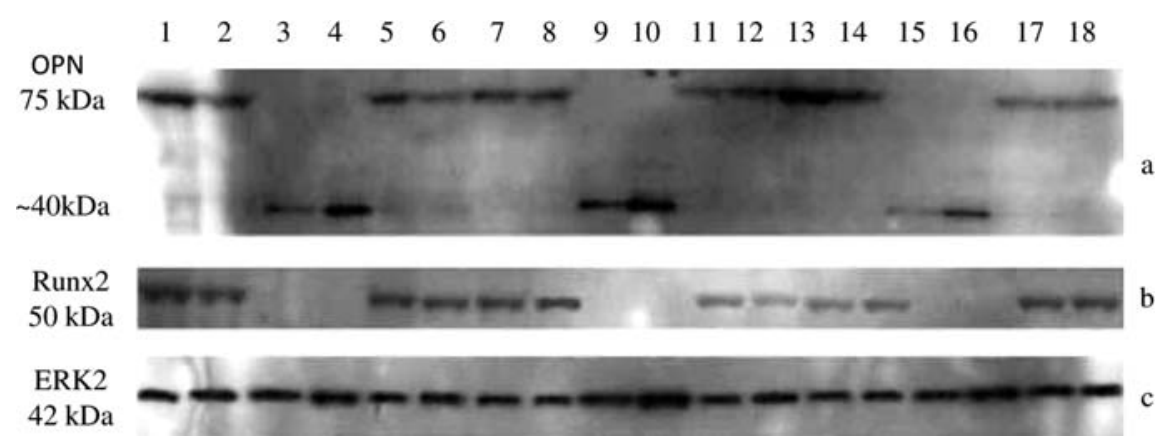

Figure 6. OPN (a), Runx2 (b) and ERK2 (c) protein expression in response to rhOPN in CC531 cells and hepatocytes as detected by Western blot. Lanes 1,7 and 13, control hepatocytes after 24,72 and 96 h, respectively. Lanes 2,8 and 14 , hepatocytes $+10 \mu \mathrm{g} / \mathrm{ml} \mathrm{rhOPN}$ after 24,72 and $96 \mathrm{~h}$, respectively. Lanes 3 , 9 and 15, control CC531 cells after 24, 72 and 96 h, respectively. Lanes 4, 10 and 16, CC531 cells $+10 \mu \mathrm{g} / \mathrm{ml} \mathrm{rhOPN}$ after 24,72 and $96 \mathrm{~h}$, respectively. Lanes 5, 11 and 17, control co-cultured CC531 cells and hepatocytes after 24, 72 and 96 h, respectively. Lanes 6, 12 and 18, co-cultured CC531 cells and hepatocytes $+10 \mu \mathrm{g} / \mathrm{ml}$ rhOPN after 24,72 and $96 \mathrm{~h}$, respectively.

Compared to controls, OPN still positively influenced the growth of CC531 cells and hepatocytes. It appeared that the cells were only slightly higher in number but they were distinctly larger and in better condition than the control cells. In contrast to OPN, TGF- $\beta 1$ caused cell death to the majority of cells and the surviving cells were smaller and seemed to be less differentiated than untreated control cells.

Effect of exogenous TGF- $\beta 1$ on CC531 cells and hepatocytes. The expression of OPN and Runx 2 was investigated in hepatocytes and CC531 cells growing separately as well as in those cells growing under co-culture conditions.

No expression of OPN and Runx2 was detected in the control or TGF-B1-treated CC531 cells. A significant increase in the expression of OPN and Runx 2 proteins was observed in hepatocytes following stimulation with TGF-ß1 (Fig. 5). This induction decreased to normal levels after $96 \mathrm{~h}$. Compared to the over-expression of these proteins in TGFB1-treated hepatocytes growing alone, OPN and Runx2 were not significantly increased in hepatocytes co-cultured with CC531 cells and treated with TGF- 31 .

Effect of exogenous OPN on CC531 cells and hepatocytes. As in the case of adding TGF- $\beta 1$, there was no expression of OPN and Runx2 in CC531 cells in either OPN-treated or control cells.

It is worth noting, that there was a $40-45-\mathrm{kDa}$ band in CC531 cells, which was not found in hepatocytes alone but which was up-regulated in OPN-treated CC531 cells. This band disappeared with time in co-cultured CC531 cells. Regarding the hepatocytes, exogenous OPN did not have a significant influence on OPN and Runx 2 expression, in contrast to TGF- $\$ 1$. As mentioned before, two bands were observed in co-cultured cells; a $75 \mathrm{KDa}$ and a $40-45-\mathrm{kDa}$ band, corresponding to hepatocytes and CC531 cells, respectively.

\section{Discussion}

Hepatic metastasis is the result of progressive colorectal cancer clones capable of independent growth, invasion, adhesion and angiogenesis. To date, a significant progress has been made in order to understand the genetic events and the associated molecular pathways underlying the development of metastatic potential. In 1889 Paget proposed in his 'seed and soil' hypothesis, that the preferential targeting of metastatic cells to particular organs is not determined entirely by mechanical or anatomical circumstances but depends also on the ability of tumor cells (seed) to find a suitable microenvironment (soil) in which to grow.

In the case of colorectal cancer metastasis, the optimal 'soil' is often the liver and one of the main compartments in this soil is hepatocytes, making up $60-80 \%$ of the cellular mass of the liver. In order to exclude the influence of other liver cells (Kupffer, Stellate and endothelial cells) or the immune system on the results, hepatocytes were isolated and used in two co-culture models. 


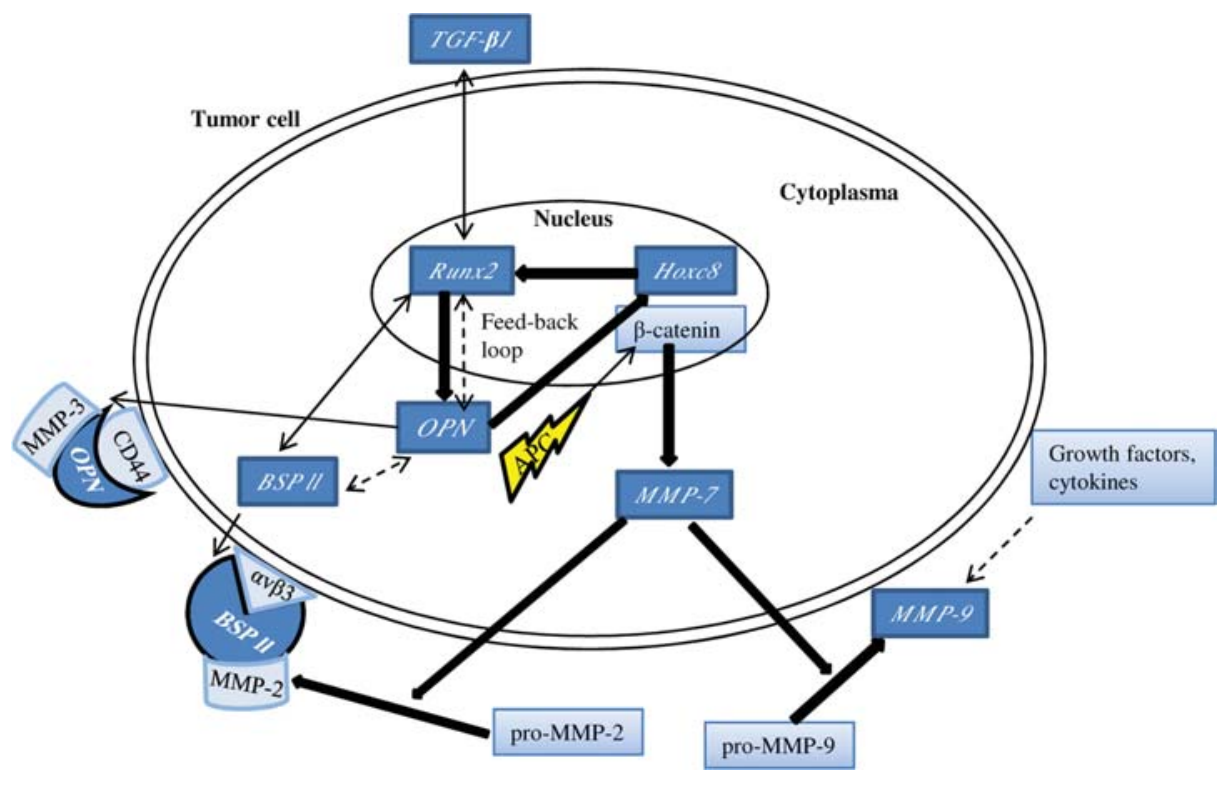

Figure 7. Illustration of pathways involved in colorectal liver metastasis as derived from this study. The genes analyzed in this study are shown in italic and bold in dark blue boxes. Thick arrows indicate a direct relationship between genes. Thin arrows indicate an indirect relationship between genes. Dotted arrows indicate a questionable relationship between genes. Two-direction arrows indicate a reciprocal relationship between genes. This figure shows the feed-back loop between Hoxc8, Runx2 and OPN; MMP-7 activation as a consequence of APC mutation; activation of MMP-2, -9 through MMP-7; binding of OPN and BSP 11 to their receptors (CD44 and integrin $\alpha v 33$, respectively) as well as to their specific MMPs (MMP-3, -2, respectively).

The list of genes involved in colorectal cancer and liver metastasis is long, and one of these genes, which may come on top of the list, is the well-known glycoprotein OPN. A recent study (10), using global gene expression microarray analysis, identified OPN as a progression marker in human colon cancer samples, which binds to the $\alpha v \beta 3$ integrin and CD44 families of receptors to propagate cellular signals, as well as to MMP-3 $(11,12)$. In our study, OPN was found to be highly expressed in CC531 tumor cells freshly explanted from the tumor. Interestingly, in cell culture the OPN mRNA disappeared with time and the OPN protein was also markedly reduced to a low level.

These findings suggest that the role of OPN may be more relevant to tumor progression and maintenance of metastases in the liver rather than to the basic biological activities of tumor cells in vitro. The OPN levels determined in vivo suggest that CC531 cells received signals in the liver environment which activated a pathway leading to the over-expression of OPN. One of the possible pathways, which could be involved, pertains to the transcription modulator Hoxc8. Hox gene deregulation is implicated in human cancers including colorectal cancer (13). A recent study, using gene oligonucleotide microarray in mouse embryo fibroblasts (MEF) in vitro, showed that the over-expression of Hoxc8 resulted in a 4.8 -fold down-regulation of OPN (14). This was confirmed by chromatin immunoprecipitation (Chip) analysis which revealed a direct interaction between the OPN promoter and the Hoxc8 protein in vivo. In concordance with these data, Hoxc8 and OPN mRNA were inversely regulated in this study. Whereas OPN was highly expressed in freshly explanted CC531 cells, Hoxc8 was very slightly expressed initially to reach its peak when OPN had disappeared. It seems that these genes are regulated in a feed-back loop, in which high levels of OPN suppress the expression of Hoxc8 which in turn repress OPN transcription when overexpressed. Shi et al (15) have demonstrated that Hoxc8 functions as an OPN transcription repressor and have also performed gel-shift assays that support the binding of Hoxc8 to the OPN promoter in vitro.

Another transcription factor which may contribute to the former 'feed-back loop' is Runx2, a member of the Runtrelated (Runx) gene family. Runx genes are known developmental regulators and have been shown to play an important role in human cancers or experimentally-induced mouse tumors. Recent data showed also that Runx 2 is involved in metastasis of breast cancer cells (16). In addition, gel-shift and Chip assays have recently revealed that Runx2 is a transcriptional regulator of OPN expression in CT26 colorectal cancer cells and the suppression of Runx 2 resulted in significant down-regulation of OPN (17). In line with this relationship, the results of our study show a concomitant expression of Runx 2 and OPN, high levels of both proteins were found initially, which then disappeared in parallel.

The suggested scenario is that the tumor cell, receiving signals from the liver microenvironment, would highly express Runx 2 and subsequently OPN. This induction of OPN by Runx 2 could be induced by TGF- $\beta 1$. However, in cell culture, where no extrinsic signals exist from the liver microenvironment, Hoxc8 would be up-regulated and thus decrease the expression of Runx2 and OPN to background levels.

The behavior of BSP 11, another member of the SIBLING family was partially like that of OPN, with the difference that the expression of OPN was higher than that of BSP 11 in freshly explanted CC531 cells. To date, the correlation between colorectal cancer and BSP 11 remains unclear, at least in tumor tissue. It was shown (18) that serum from patients with lung and colon cancer exhibited high levels of one marker with low levels of the other although some 
cancers (breast and prostate) showed high levels of both proteins, BSP 11 and OPN.

In the current study, the expression of BSP 11 could not be easily elucidated as it was gradually down-regulated followed by a sudden over-expression. This needs to be explained in future studies concentrating on its interaction with MMP-2 and the cell-surface integrin $\alpha v ß 3$. A previous study (19) demonstrated that BSP 11 enhances cancer cell invasiveness by forming a trimolecular complex with MMP-2 and the cellsurface integrin $\alpha v \beta 3$, which means that BSP 11 expression, may also be influenced by expression of the $\alpha v \beta 3$ receptor on tumor cells and/or MMP-2.

One of the initial steps of metastasis is the degradation of basement membranes and the removal of physical barriers to invasion. The main contributors to this process in colorectal cancer are MMPs, particularly MMP-2, MMP-9 and MMP-7 $(20,21)$.

Activated forms of MMP-9 and MMP-2 are correlated with colorectal cancer and liver metastasis (20). Furthermore, it was previously shown in colorectal cancer that the MMP-9 mRNA and protein are localized in tumor stroma rather than tumor cells themselves (22). According to the data in this study, MMP-9 mRNA was expressed in the tumor cells themselves. Unexpectedly, the expression of MMP-9 mRNA was higher in tumor cells in vitro than in freshly explanted CC531 cells, at least after the first and fifth passages. However, the detection of MMP-9 at the mRNA level only is insufficient to understand its correlation with the invasive metastatic behavior, since it does not differentiate between latent MMP-9 precursors (proenzymes) and their activated forms. Up-regulation of MMP-9 mRNA in vitro indicates at least the activation of a pathway leading to MMP-9 expression. In contrast to MMP-9, the active MMP-7 enzyme was very highly expressed in the metastases explanted from the liver and then decreased in cell culture, without disappearing. It has been reported (21) that the MMP-7 mRNA and protein were over-expressed in colorectal liver metastases as compared with normal liver tissue, with a preferential localization in the cytoplasm of tumor cells concentrated in the tumor front area. Moreover, MMP-7 was further linked to colorectal cancer through its over-expression as a result of APC/ 3 -catenin pathway mutations (23). These data confirm the crucial role of MMP-7 in the degradation of ECM in primary tumor as well as in tumor invasion and metastasis.

In order to better understand the observations in the first part of the study, hepatocytes were isolated and used in two co-culture models. The co-culture/two compartment model was performed in an attempt to separate the key players found in a metastatic liver. For this reason, CC531 tumor cells were co-cultured but separated from hepatocytes by $0.4-\mu \mathrm{m}$ pore size membranes. This pore size allows only soluble growth factors, cytokines and substances secreted from each compartment to pass through, thus limiting cellcell interactions. No expression of OPN and Runx 2 in these co-cultured tumor cells was detected. These observations suggest that other factors contribute to the over-expression of OPN and Runx 2 in tumor cells and hepatocytes in vivo.

In order to investigate the effect of cell-cell interactions and/or some growth factors and cytokines, the co-culture/one compartment model was established. It is no surprise to find that OPN and Runx2 were over-expressed in TGF- 31 -treated hepatocytes, because Runx transcription factors appear to be associated with the TGF- $\beta$ superfamily signaling pathway (24). Also, the TGF- 31 signal activates the Runx2 gene transcriptionally (25).

However, there was no over-expression of Runx 2 and OPN in TGF-ß1-treated hepatocytes which were co-cultured with CC531 cells, indicating that the response of the hepatocytes was abrogated by CC531 cells. TGF- $B 1$ has been reported to be expressed locally in many human tumors including colorectal cancer, and is believed to play a role in tumor metastasis and progression (26-28). The role of TGF- 31 in tumor progression of CC531 cells, however, is questionable. Hepatocytes are unlikely to stimulate OPN expression in CC531 cells in response to TGF- 31 induction. A leading role of the other cell types of the liver has to be assumed instead.

In conclusion, OPN, Runx 2 and MMP-7 were found to be highly expressed in CC531 metastases explanted from the liver but showed subsequent down-regulation and/or disappearance in cell culture. The inverse regulation of Hoxc8, OPN and Runx2 suggests that these genes may be regulated in a feed-back loop manner (Fig. 7). MMP-9 mRNA and active MMP-7 protein were expressed in tumor cells themselves. The presence of hepatocytes was insufficient to induce induction of OPN and Runx 2 in tumor cells in vitro, so was the addition of OPN or TGF- $\beta 1$. Whereas TGF- $\beta 1$ induced over-expression of OPN and Runx2 in hepatocytes, it did not exert the same effect on hepatocytes co-cultured with CC531 cells, indicating that this response was abrogated by CC531 cells.

\section{Acknowledgments}

This work was financially supported by a scholarship from Al-Baath University in Syria, with a special thank to Dr Emad Al Haddad, Dean of the Faculty of Pharmacy for his supervision and continuous support.

\section{References}

1. Soussi T: The p53 tumour suppressor gene: a model for molecular epidemiology of human cancer. Mol Med Today 2: 32-37, 1996.

2. Wanebo HJ, Semoglou C, Attiyeh F and Stearns MJ Jr: Surgical management of patients with primary operable colorectal cancer and synchronous liver metastases. Am J Surg 135: 81-85, 1978.

3. Choti MA, Sitzmann JV, Tiburi MF, et al: Trends in long-term survival following liver resection for hepatic colorectal metastases. Ann Surg 235: 759-766, 2002.

4. Fong Y, Fortner J, Sun RL, Brennan MF and Blumgart LH: Clinical score for predicting recurrence after hepatic resection for metastatic colorectal cancer: analysis of 1001 consecutive cases. Ann Surg 230: 309-321, 1999.

5. Scheele J, Stang R, Altendorf-Hofmann A and Paul M: Resection of colorectal liver metastases. World J Surg 19: 59-71, 1995.

6. Zacharias T, Jaeck D, Oussoultzoglou E, Bachellier P and Weber JC: First and repeat resection of colorectal liver metastases in elderly patients. Ann Surg 240: 858-865, 2004.

7. Koch M, Weitz J, Kienle P, et al: Comparative analysis of tumor cell dissemination in mesenteric, central, and peripheral venous blood in patients with colorectal cancer. Arch Surg 136: 85-89, 2001.

8. Stetler-Stevenson WG, Aznavoorian S and Liotta LA: Tumor cell interactions with the extracellular matrix during invasion and metastasis. Annu Rev Cell Biol 9: 541-573, 1993. 
9. Obrink B: Hepatocyte-collagen adhesion. Methods Enzymol 82A: 513-529, 1982

10. Agrawal D, Chen T, Irby R, et al: Osteopontin identified as lead marker of colon cancer progression, using pooled sample expression profiling. J Natl Cancer Inst 94: 513-521, 2002.

11. Sodek J, Ganss B and McKee MD: Osteopontin. Crit Rev Oral Biol Med 11: 279-303, 2000.

12. Fedarko NS, Jain A, Karadag A and Fisher LW: Three small integrin binding ligand N-linked glycoproteins (SIBLINGs) bind and activate specific matrix metalloproteinases. FASEB J 18: 734-736, 2004

13. De Vita G, Barba P, Odartchenko N, et al: Expression of homeobox-containing genes in primary and metastatic colorectal cancer. Eur J Cancer 29A: 887-893, 1993.

14. Lei H, Wang H, Juan AH and Ruddle FH: The identification of Hoxc8 target genes. Proc Natl Acad Sci USA 102: 2420-2424, 2005 .

15. Shi X, Yang X, Chen D, Chang Z and Cao X: Smad1 interacts with homeobox DNA-binding proteins in bone morphogenetic protein signaling. J Biol Chem 274: 13711-13717, 1999.

16. Barnes GL, Javed A, Waller SM, et al: Osteoblast-related transcription factors Runx2 (Cbfa1/AML3) and MSX2 mediate the expression of bone sialoprotein in human metastatic breast cancer cells. Cancer Res 63: 2631-2637, 2003.

17. Wai PY, Mi Z, Gao C, Guo H, Marroquin C and Kuo PC: Ets-1 and runx 2 regulate transcription of a metastatic gene, osteopontin, in murine colorectal cancer cells. J Biol Chem 281 18973-18982, 2006

18. Fedarko NS, Fohr B, Robey PG, Young MF and Fisher LW: Factor $\mathrm{H}$ binding to bone sialoprotein and osteopontin enables tumor cell evasion of complement-mediated attack. J Biol Chem 275: 16666-16672, 2000.

19. Karadag A, Ogbureke KU, Fedarko NS and Fisher LW: Bone sialoprotein, matrix metalloproteinase 2, and alpha(v)beta3 integrin in osteotropic cancer cell invasion. J Natl Cancer Inst 96: 956-965, 2004
20. Zeng ZS and Guillem JG: Unique activation of matrix metalloproteinase-9 within human liver metastasis from colorectal cancer. Br J Cancer 78: 349-353, 1998.

21. Zeng ZS, Shu WP, Cohen AM and Guillem JG: Matrix metalloproteinase-7 expression in colorectal cancer liver metastases: evidence for involvement of MMP-7 activation in human cancer metastases. Clin Cancer Res 8: 144-148, 2002.

22. Zeng ZS and Guillem JG: Colocalisation of matrix metalloproteinase-9-mRNA and protein in human colorectal cancer stromal cells. Br J Cancer 74: 1161-1167, 1996.

23. Brabletz T, Jung A, Dag S, Hlubek F and Kirchner T: betacatenin regulates the expression of the matrix metalloproteinase-7 in human colorectal cancer. Am J Pathol 155: 1033-1038, 1999.

24. Ito Y: Oncogenic potential of the RUNX gene family: overview. Oncogene 23: 4198-4208, 2004.

25. Lee KS, Kim HJ, Li QL, et al: Runx2 is a common target of transforming growth factor betal and bone morphogenetic protein 2, and cooperation between Runx2 and Smad5 induces osteoblast-specific gene expression in the pluripotent mesenchymal precursor cell line $\mathrm{C} 2 \mathrm{C} 12$. Mol Cell Biol 20: 8783-8792, 2000.

26. Markowitz S, Wang J, Myeroff L, et al: Inactivation of the type II TGF-beta receptor in colon cancer cells with microsatellite instability. Science 268: 1336-1338, 1995.

27. Huang F, Newman E, Theodorescu D, Kerbel RS and Friedman E: Transforming growth factor beta 1 (TGF beta 1) is an autocrine positive regulator of colon carcinoma U9 cells in vivo as shown by transfection of a TGF beta 1 antisense expression plasmid. Cell Growth Differ 6: 1635-1642, 1995.

28. Padua D and Massague J: Roles of TGFbeta in metastasis. Cell Res 19: 89-102, 2009. 